\title{
On an Argument of Segal's Against Singular Object-dependent Thoughts
}

\author{
Teresa Marques \\ Philosophy Centre of the University of Lisbon \\ LOGOS, University of Barcelona
}

Disputatio Vol. 2, No. 21

November 2006

DOI: $10.2478 /$ disp-2006-0012

ISSN: 0873-626X 


\title{
On an argument of Segal's against singular object-dependent thoughts
}

\author{
Teresa Marques ${ }^{1}$ \\ Philosophy Centre of the University of Lisbon \\ LOGOS, University of Barcelona
}

\begin{abstract}
This paper discusses and criticizes Segal's 1989 argument against singular object-dependent thoughts. His argument aims at showing that object-dependent thoughts are explanatorily redundant. My criticism of Segal's argument has two parts. First, I appeal to common anti-individualist arguments to the effect that Segal's type of argument only succeeds in establishing that object-dependent thoughts are explanatorily redundant for those aspects of subjects' behaviour that do not require reference to external objects. Secondly, Segal's view on singular thoughts is at odds with his view on the semantics of proper names, which favours the singularity and object-dependency of the truth-conditions of sentences in which they occur. In particular, his views are at odds with a position he holds, that truth-conditional semantics can adequately account for all aspects of speakers' linguistic competence in the use of proper names.
\end{abstract}

Reference failure seems problematic because of the conflict between two requirements. On the one hand, there are requirements on the singularity and object-dependency of the truth-conditions of sentences with proper names. On the other hand, there are requirements on behavioural and psychological explanation, motivated by a strong intuition that people nonetheless understand utterances of sentences with vacuous terms, namely proper names: they take those sentences to have a truth-value and use them to express their beliefs, thoughts, desires, etc. The first requirement is often formulated in terms of thought expression. Just as truth-conditions are object-

${ }^{1}$ Work supported by the postdoctoral research fellowship SFRH/BPD/16678/ 2004 (FCT), project Content, POCI/FIL/55562/2004 (FCT), at the Philosophy Centre of the University of Lisbon and project Ontological Dependence, HUM200405609-C02-01 (MEC), at the LOGOS group of the University of Barcelona.

Disputatio, Vol. II, No. 21, November 2006 
dependent, so are singular object-dependent thoughts about different objects different thoughts, and a singular object-dependent thought would not have existed had its object not existed. It is taken as a consequence of this view that, if proper names contribute to objectdependent truth-conditions, then vacuous proper names do not contribute to truth-conditions, and in the absence of truth-conditions we simply fail to have singular object-dependent thoughts.

This paper discusses and criticizes Gabriel Segal's 1989 argument against singular object-dependent thoughts, mostly as applied to proper names. Segal's argument aims at showing that objectdependent thoughts are explanatorily redundant. My criticism of Segal's argument has two parts. First, I appeal to the common antiindividualistic criticism of Segal's type of argument, to the effect that the argument only succeeds in establishing that object-dependent thoughts are explanatorily redundant for those aspects of subjects' behaviour that do not require reference to external objects. Secondly, Segal's view on singular thoughts is at odds with his view on the semantics of proper names, which favours the singularity and objectdependency of the truth-conditions of sentences in which they occur. Yet, it is not possible to hold that vacuous names make a 'meaningful contribution' to sentences in which they occur, that they contribute to singular object-dependent truth-conditions, and to hold that truthconditional semantics can adequately account for all aspects of speakers' linguistic competence in the use of proper names.

In section 1, I present what we may call the strong singular objectdependent thought view (SOT, henceforth), especially McDowell's position, and how it agrees with plausible requirements on truthconditions, but seems to conflict with requirements on psychological and behavioural explanation. In section 2, I explain Segal's individualistic argument against SOT. Next, in section 3, I put forward the usual criticism against individualistic type of arguments, in particular against the individualistic assumption that two subjects behave and think alike if they are functionally and physiologically identical. This ignores relevant aspects of behaviour and mental states that require successful reference to external objects. In the final section, 4, I present reasons to doubt Segal's defence of the individualistic assumption, and I draw attention to the internal conflict in Segal's views, as mentioned in the previous paragraph. 


\section{Conflicting requirements: singularity, truth-conditions and thought-expression}

Truth-conditional semantics rests on the assumption that the sufficient and necessary conditions for the truth of a sentence (or an utterance of a sentence in a context) give the sentence's meaning or significance. So, by stating truth-conditions one accounts for a sentence's meaning. Likewise, the meaning of expressions and phrases is accounted for by stating their systematic contribution to the truthconditions of the sentences in which they occur. The idea is sometimes expressed by saying that, for instance, to know the meaning of a sentence is to know its truth-conditions, that a competent speaker understands a sentence, or an utterance of a sentence in a context, when he knows when it would be true.

The kind of expressions usually designated as singular terms are brought together under the same category because of their similarities of function and use in language. Fundamentally, the type of truthconditions of utterances of sentences containing singular terms are thought to be not only singular, i.e., satisfied by one only individual, but also object-dependent, i.e., dependent on the existence and identity of the object referred to with the singular term. Proper names are usually classified under this category of terms. ${ }^{2}$

Singular terms are thought to be distinct from other expressions with claims to singularity, in particular definite descriptions. One way to state the difference is to say that definite descriptions contribute to singular truth-conditions, i.e., satisfied at most by one individual, but object-independent, indifferent to which, if any, object satisfies them. Concerns of Kripkean inspiration lend support to the view that proper names should be viewed in the category of singular terms, rather than in the category of definite descriptions. Proper names thus contribute to the singularity and object-dependency of the truthconditions of (most?) sentences containing them:

\footnotetext{
${ }^{2}$ This view is not universally endorsed, obviously, but it is notoriously defended by Evans 1982 and McDowell 1977 and 1982, for example. It also underlies the thesis of the rigidity of singular terms, and the arguments usually advanced to distinguish definite descriptions from singular terms such as proper names. Cf. Peacocke 1975, Kripke 1980, Neale 1990, Larson and Segal 1995, for instance.
} 
(STC) Singular truth-conditions about different individuals are different truth-conditions, and if no object is referred, there are no truthconditions to convey.

This view on proper names can be formulated in terms of thought expression. This is the thesis of the singularity and object-dependency of thoughts. And here, the designation 'singular' abbreviates again 'singular and object-dependent':

(SOT) Singular thoughts about different individuals are different singular thoughts, and if there is no individual thought about, there is no thought to be entertained.

John McDowell's 1977, 1982 defence of the SOT thesis, for instance, has a particular flavour, because of the endorsement of a Davidsonian truth-conditional view of meaning. He says:

An interesting way to raise questions about the relation between language and reality is to ask: how could we state a theory knowledge of which would suffice for understanding a language? Donald Davidson has urged that a central component in such a theory would be a theory of truth, in something like the style of Tarski, for the language in question. A Tarskian truth-theory entails, for each indicative sentence of the language it deals with, a theorem specifying a necessary and sufficient condition for the sentence to be true. The theorems are derivable from axioms which assign semantic properties to sentence-constituents and determine the semantic upshot of modes of combination. Now Frege held that the senses of sentences can be determined by giving truthconditions, and that the sense of a sentence constituent is its contribution to the senses of sentences in which it may occur. The parallel is striking. It suggests a construal of Davidson's proposal as a proposal about the nature of a theory of (Fregean) sense for a language. (McDowell 1977: 159)

Proper names are said to contribute with their referents to the truthconditions of sentences. By drawing a parallel between the Davidsonian thesis and the Fregean idea that the senses of sentences can be determined by giving truth-conditions, McDowell claims that in stating the semantic value, i.e. the reference, of a proper name we display the sense of the name. So, for instance, typical axioms of the theory like (1) state the reference (and 'display the sense') of 'Michael Jordan': 
(1) 'Michael Jordan' stands for Michael Jordan.

McDowell, like Evans 1982, extends this claim to singular thoughts and attributions of propositional attitudes. The connection made is stated in McDowell's 1982 justification for the thesis that an utterance of an atomic sentence containing an empty singular term is neither true nor false:

The syntax of sentences of the relevant sort fits them to express singular thoughts if any; where a singular thought is a thought that is not available to be thought or expressed if the relevant object, or objects, did not exist. It follows that if one utters a sentence of the relevant sort, containing a singular term that, in that utterance, lacks a denotation, then one expresses no thought at all; consequently, neither a truth nor a falsehood. (McDowell 1982: 303-4)

McDowell's position can be summarized thus: there is no truthevaluable content when reference failure occurs, since 'the syntax of sentences of the relevant sort' constrains the truth-conditions of such sentences to be singular and object-dependent. If there are no truthconditions, then there is no thought-content. There is often no guarantee that one will succeed in referring to a particular object by using a proper name. According to the view sketched above, if one's utterance of a sentence has no truth-conditions, then it also has no truthconditions and therefore also no significance or meaning. Likewise, an utterance of such a sentence fails to express a singular thought.

One example used to illustrate SOT is given originally by McDowell 1977: 'Mumbo-Jumbo' is the name for a god of a distant tribe, but there is no Mumbo-Jumbo. Even if we adopt the notion of sense as a mode of presentation or way of thinking of an object, which is displayed in the clauses stating the reference of proper names like (1), it would not follow, as Frege 1892 held, that names could have senses but no referents. If a name has no referent, then we cannot state the appropriate clause for that name in the theory, nor state the truth-conditions of sentences where the name occurs. Consider the 'Mumbo-Jumbo' example.

(2) 'Mumbo-Jumbo' stands for ???

Since there is no referent for 'Mumbo Jumbo', its reference cannot be stated, and it cannot make any systematic contribution to the 
truth-conditions of sentences in which it occurs. Equally, there is no sense to be displayed in a clause like (2). Hence, a sentence like 'Mumbo-Jumbo brings thunder' is neither true nor false because the name in it makes no contribution to truth-conditions, and no contribution to content-specifications. The natives of the distant tribe cannot believe that Mumbo-Jumbo brings thunder, because there is no Mumbo-Jumbo.

But this is counterintuitive; it seems that natives of such a tribe understand (as we seem to do) what 'Mumbo-Jumbo brings thunder' means, and they apparently do believe that Mumbo-Jumbo brings thunder. How can we explain what they say, mean and do if such a sentence has no significance/expresses no singular thought? And what is it that they (or we) understand?

Reference failure seems to be problematic because of the apparent conflict between two requirements. On the one hand, truthconditional considerations seem to motivate the thesis of the objectdependency and singularity of the thoughts expressed. On the other hand, there are many arguments to the effect that proper psychologi$\mathrm{cal}$ and behavioural explanations require some content to be ascribed as the content of beliefs and thoughts, whether or not reference to an object is successful. It is not clear whether the two requirements are irreconcilable. Do proper psychological and behavioural explanations require singular content to be ascribed to a subject whether or not singular reference is successful, or do concerns with truth-conditions forbid the assignment of any thought-content to mistaken subjects?

Two standard and straightforward options to deal with the dilemma are to (a) permit the expression of singular thought content irrespectively of the identity or existence of a particular object, and hence loose the claim to object-dependency; (b) alternatively, reject the claim that psychological and behavioural explanation requires the assignment of singular content whether or not a particular object is referred. In this case, alternative explanations must be put forward. McDowell endorses (b), as we just saw.

But Gabriel Segal 1989 has argued in favour of (a) above, and against (b). His paper advances the usual individualistic argument 
against externalist accounts of content, but with a twist. ${ }^{3}$ I will next present Segal's argument.

\section{Segal's argument against singular object-dependent thoughts}

Segal's criticism of the SOT thesis is, essentially, that it 'cannot make sense of the actions of subjects of empty singular thoughts, thoughts containing a component that purports to refer to a specific object, but in fact lacks a referent.' (Segal 1989: 40), or at least it cannot do so without undermining itself.

Segal's criticism is a variation on the usual individualistic argument against singular object-dependent thoughts. The usual argument goes as follows. We are to imagine that there are two groups of subjects in suitably different environments. It is first assumed that the two groups behave in the same way if they are identical in certain relevant respects, for instance, physiologically and functionally identical. Secondly, it is assumed that the requirements on psychological and behavioural explanations require the same explanation for the same behaviour. The conclusion is that two groups of subjects who behave in the same way should receive the same explanation, which includes the ascription of the same mental contents.

Now, the SOT theorist claims that singular object-dependent thoughts existence and identity depends on the existence and identity of the object of thought, and when there is no referred object, there is no singular thought. But how does a non-thought cause and provide rationale for intentional action? How can the SOT theorist explain the apparent plausibility of saying that natives believe that Mumbo-Jumbo brings thunder? The SOT theorist needs to offer some explanation of this.

McDowell, for example, suggests that when it is not possible to ascribe to someone a singular belief or thought, the subject must be described as having some second order beliefs. ${ }^{4}$ Arguably, the subject

\footnotetext{
${ }^{3}$ Similar criticism has been offered for example by Blackburn, 1984: chapter 4, or Carruthers 1987.

4 'A sincere assertive utterance of a sentence containing a name with a bearer can be understood as expressing a belief correctly describable as a belief, concerning the bearer, that it satisfies some specified condition [in footnote: that is, describable by way of a transparent, or relational, attribution of belief]. If the name has no
} 
may also have other first order descriptive beliefs associated with the use of that name. As he claims, a subject meant to express a thought describable in the transparent style, and this is what is required by 'a proper respect for a person's authority on his own thoughts' (McDowell 1977: 175).

Now, Segal argues, if it is sufficient to ascribe second order beliefs to explain mistaken subject's attitudes and actions, then objectdependent singular thoughts become explanatorily redundant. If they are not necessary to explain the attitudes and actions of mistaken subjects, then they are equally unnecessary to explain the attitudes and actions of non-mistaken subjects.

Segal develops his version of the usual individualist argument by appealing to a common Twin-Earth thought-experiment. Take the example 'Mumbo-Jumbo brings thunder'. A native of a distant tribe utters the sentence because he believes there is a god, called 'MumboJumbo', who brings thunder. But there is no Mumbo-Jumbo on Earth. If there is no thought-content to attribute to the native, then we must find another explanation for his actions. Suppose then that there is such an explanation, in the form of a set $X$ of beliefs and desires (including the native's second order beliefs) that would give them sufficient reason for saying 'Mumbo-Jumbo brings thunder' .

Suppose, also, that there is a Twin-Earth twin to the Earth's native, exactly alike the Earth's native, except on Twin-Earth there is a Mumbo-Jumbo god. On Twin-Earth, the native's utterance of 'Mumbo-Jumbo brings thunder' is true. The twin-native must have all of the beliefs and desires in $X$. If $X$ explains the native's actions on Earth, it will be sufficient to explain the twin-native's actions on Twin-Earth, and hence it also explains his utterance of 'MumboJumbo brings thunder'. But the object-dependent or de re belief that Mumbo-Jumbo brings thunder (which would be, on assumption, attributable to the twin-native, but not to the native) is explanatorily redundant. Hence, object-dependent thoughts are not necessary to provide psychological and behavioural explanations.

bearer (in the interpreter's view), he cannot describe any suitably related belief in the transparent style. He can indeed gather, from the utterance, that the subject believes himself to have a belief that could be thus described, and believes himself to be expressing such a belief by his words. That might make the subject's behaviour, as speaking as he does, perfectly intelligible; but in a way quite different from the way in which, in the first kind of case, the belief expressed makes the behaviour intelligible.'(McDowell 1977, 172-3) 
Notice that the thought-experiment follows the usual argument against the SOT thesis. It is assumed that the behaviour of both groups of natives is the same on Earth and on twin-Earth, irrespectively of relevant environmental changes. It is then also assumed that behavioural explanation, including thought ascriptions, must be common in both cases, and it is concluded that this can be done without positing object-dependent thoughts.

The plausibility of Segal's variation on the usual argument against the SOT thesis rests on the original plausibility of the usual argument against the SOT thesis, and is therefore subject to the same objections as the assumptions on which the usual argument rests - it assumes, namely, that subjects in suitably different environments behave in the same way. But this ignores the relational aspects of behaviour and mental states, which cannot be the same in different environments.

\section{Are object-dependent thoughts explanatorily redundant? The usual rejoinder to the individualistic argument}

The plausibility of Segal's argument rests on the plausibility of its assumptions. It might be granted that the same behaviour should receive the same explanation (the second assumption of the usual individualistic argument). So, the question concerns the plausibility of the first assumption, that both groups of natives behave alike.

The usual argument assumes that two subjects (or groups of subjects) who are functionally and physiologically identical behave in the same way, even if their environments are distinct in important respects. Denying this, Burge says

Apart from methodological bias, it is just not true that descriptions that would count as 'behavioural' in cognitive (social, developmental) psychology would apply to both the protagonists... The general point is that many relevant specifications of behaviour in psychology are intentional, or relational, or both... One must look at what psychology actually takes as 'behavioural' evidence. It is the responsibility of the argument to show that non-individualistic notions have no place in psychology. Insofar as the argument assumes that intentional, non-individualistic specifications of behaviour are illegitimate, it either ignores obvious aspects of psychological practice or begs the question at issue. (Burge 1986: 11-12) 
Burge remarks that physiological and functional states are insufficient for correct behavioural and psychological explanations - we need only look at what psychology actually takes as evidence to confirm it. So, the assumption made by the individualist is unfounded.

In particular, the individualist neglects, when he argues against the SOT theorist, that there are actions and beliefs of non-deluded subjects that cannot be ascribed to the deluded subjects, namely those that can be ascribed under a relational description. The non-deluded subject on twin-Earth believes, of Mumbo-Jumbo ${ }^{\text {twin-earth }}$, that he brings thunder. Mumbo-Jumbo ${ }^{\text {twin-earth }}$ is such that the non-deluded native worships him, and he rewards the native for his devotion. He believes, truly, that Mumbo-Jumbo ${ }^{\text {twin-earth }}$ brings thunder. Both the native's actions and beliefs are suitably related to Mumbo-Jumbo ${ }^{\text {twin-earth }}$.

Suppose there is a third world, Twintwin-Earth, where there is also a group of natives who utter 'Mumbo-Jumbo brings thunder', and display what counts as the same behaviour, by the individualist lights. On Twintwin-Earth there is a god, Mumbo-Jumbo ${ }^{\text {twintwin-earth }}$, who does not bring thunder. Here natives also utter 'Mumbo-Jumbo brings thunder', but they believe, falsely, that Mumbo-Jumbo ${ }^{\text {twintwin- }}$ earth brings thunder, and worship Mumbo-Jumbo ${ }^{\text {twintwin-earth }}$.

The point is not only about which divine entity natives worship, i.e., that behavioural specifications must incorporate relational descriptions to the appropriate entity. It is that the mental states ascribed must also be suitably related to the appropriate objects of belief. This receives further support from the consideration that beliefs and other mental states are partly individuated by their truthconditions. At best, we can describe Twintwin-Earth's natives and Twin-Earth's natives as sharing a number of common, descriptive beliefs that there is a god called 'Mumbo-Jumbo', that he has thunder bringing powers, and as uttering 'Mumbo-Jumbo brings thunder'.

The variation in the truth-value of natives' beliefs is due to their different truth-conditions. The beliefs are about different gods, even if the gods have the same name and are believed to have the same thunder-bringing powers. We already seem to have sufficient reasons to doubt whether we can ascribe the same belief, that Mumbo-Jumbo brings thunder, to these two groups of natives without bringing in Earth's natives. We know that we can describe Earth's natives as sharing the same descriptive beliefs with their Twin-Earth and Twintwin-Earth's counterparts. But we cannot ascribe the same behaviour, or beliefs about the same entity, to the three groups. 
Now, Segal's argument rests on the same assumptions as the usual individualistic argument. Because of this, Segal's argument is subject to the same type of objections as the usual argument is. One of the assumptions is that two subjects in the same internal state behave in the same way and have the same mental states. On the actual ascriptions of mental content and descriptions of behaviour, that is not the case. Descriptions of behaviour make reference to the relevant relata, and ascriptions of mental content involve truth-conditions. Insofar as truth-conditions are dependent on the object referred to, and content is individuated by truth-conditions, so are the corresponding mental contents and states.

Segal is persuaded that his argument against SOT has established that object-dependent thoughts are explanatorily redundant. Given the assumption on which his argument rests, the argument fails to show this. On the contrary, the supposition of object-dependent mental states coheres with the evidence available for psychological and behavioural explanations.

Of course, Segal can provide an alternative explanation to defend the individualistic assumption, supplementing it with a further elucidation of how and why reference to existing external objects is relevant for the attribution of mental states. But this diminishes the force of Segal's point. He is no longer showing straightforwardly that object-dependent thoughts are explanatorily redundant. He is now trying to show that we can dispose of the explanatory strength of object-dependent thoughts in the cases where reference is successful, and replace it with an alternative supplemented internalist account of mental content. The burden of proof has shifted: it is the individualist's responsibility to prove that the new supplemented account of mental contents can perform as well as object-dependent content does in successful cases of reference.

In the next and final section, I will consider reasons to doubt this, and draw attention to an internal conflict in Segal's position.

\section{5. 'Anything you can do, I can do better'?}

Can content be specified in purely individualistic terms, and perform as well as object-dependent content does in successful cases of reference? The issue is complex and difficult to approach. It cannot receive here a full treatment, but I will consider some reasons to doubt the 
possibility of its success. For it to be successful, purely individualistic content must enter in the explanation and causation of every state and action in which object-dependent content adequately enters.

Segal advances a suggestion on how to achieve this, which would defend the above-mentioned individualistic assumption of the argument. Appealing again to the set $X$ of beliefs and desires mentioned earlier, Segal says that even if $X$ alone cannot explain native's actions, $X$ combined with the native's external circumstances can. (cf. Segal 1989: 44)

Segal must spell out what are those beliefs which, combined with a subject's external circumstances, explain why a subject says what he says, does what he does, etc., in relation to a given object. Segal wants, in the Mumbo-Jumbo case, that a native utters 'Mumbo-Jumbo brings thunder' because he believes that Mumbo-Jumbo brings thunder.

But singular thoughts are thoughts about particular objects; and a thought is about a particular object only if its truth-conditions involve the object:

A singular thought $a$ is $F$ is about $a$, one would think, because it is true iff $a$, in particular, is $F$. So there is a problem for those of us who wish for a reference-independent psychological taxonomy. If taxonomy is by content and the only sort of content a singular thought has is given by its truth conditions, then it is hard to avoid [SOT theory]: the truth conditions of singular thoughts are object dependent by the very nature of such things (Segal 1989: 49).

Segal purports to solve the 'problem' by adapting a proposal from Burge $1977^{5}$ : singular thoughts have the logical form of open sentences, with places for subject components and predicate components. The open sentences, like the incomplete thoughts, would lack truth-conditions, since not all their semantic values are determinable independently of the objects given contextually. Suppose, for example, that Orville utters

(3) I should reach for that olive.

What Orville says has the form olive $(x)$ and I should reach for $(x)$. If there is an olive in the environment of Orville for him to demon-

\footnotetext{
${ }^{5}$ Not exactly in the same spirit as Burge in his defence of the virtues of de re belief.
} 
strate, then that olive becomes the value of $x$. Or so the story is supposed to go. One might find it peculiar that people entertain thoughts lacking not only truth-values, but also truth-conditions; i.e., we might find it very doubtful that we can have beliefs that are neither correct nor incorrect in given circumstances, and that such contents perform an adequate role in rational behaviour.

This worry is expressed by Evans 1982, for instance, who argued against this supposition by saying that thoughts are representational states, and as such must be assessable as true or as false, since a representational state 'represents something other than itself as being thus and so, with the consequence that the state is true if and only if the thing concerned is thus and so' (Evans 1982: 202). But an incomplete thought schema is not evaluable, hence it is not representational.

One might reply that this charge is unfair, since Segal accepts that we must assign entities as values to singular terms. What exists when there is no object referred is representational in the sense, perhaps, that it is apt to become truth-conditional. But I do not think Segal's position is as simple as he would like it to be. In fact, I believe he is offering us singular but object-independent thoughts, with singular but object-independent truth-conditions. To see this, we need only consider how he develops the explanation of such contents. Consider Orville again, failing to demonstrate any olive:

When we try to describe Orville's action what we find ourselves saying is: Orville is reaching for the olive that he thinks is there. When we talk like this we are trying to describe the action in a way that captures how Orville himself conceives of it, but we are trying to do so without referring to an olive. The idea is that Orville thinks that there is a particular olive in front of him, one that he thinks of as just that olive. And what he takes himself to be doing is reaching for that olive - the olive he thinks is there. We say 'he is trying to reach for the olive he thinks is there' because we are trying to say that he is reaching for an olive, which is what he thinks he is doing, without committing ourselves to there being an olive that he is reaching for. (Segal 1989: 55)

Why does this amount to a singular object-independent specification of content, with truth conditions? Segal has offered several descriptions, all of which are perfectly adequate insofar as we are giving an explanation of someone who (mistakenly) thinks there is an olive present in his surroundings: 'the olive Orville thinks is there'. What does Segal say, correctly, that Orville thinks? He thinks there is an 
olive in front of him, and he thinks of it as that olive. But Segal has not specified an empty demonstrative thought. The demonstrative 'that olive' here is anaphoric for the olive Orville thinks is there, i.e., for a description. ${ }^{6}$ So, Segal is giving us descriptions that may or may not apply to given objects in a subject's environment. Hence, if that is all there is to singular thoughts, it is certainly plausible to say that a subject would have entertained the same thought, whatever object, if any was 'referred'. That is the way descriptions function - they are singular, but object-independent.

Now, one of the problematic aspects of this view is the claim that these object-independent contents, are sufficient to cause and provide explanations for the actions of subjects that successfully refer to objects in their environment. So, if we imagine Orville's twin, reaching for an olive he sees, we must ascribe to him the same belief we ascribe to Orville. The context just happens to provide an olive that can be demonstrated. Similar explanations must be available for uses of vacuous proper names, and those explanations must do the work in the causal explanation of action. To see why this is a problematic view to hold, we need to consider a successful case of reference, for instance with a proper name like 'Michael Jordan'.

Williamson 2000 has argued that the causal efficacy of factive mental states, in particular knowledge, cannot be performed to the same degree by non-factive mental states. The individualist is aiming for belief, not knowledge, in the causal explanation of action. However, as Williamson says, 'Much needs to be probed and questioned in these internalist ideas. We should not assume that the notion of causal efficacy is clear, or derived from fundamental science, or known to apply only to local connections'. (Williamson 2000: 61).

Suppose Orville is also an NBA fan, has followed Michael Jordan's career, and would do anything to get an autograph. So much so that he spent last night awake outside the hotel where Michael Jordan is sleeping, to finally meet Jordan and ask him for an autograph. Orville has seen Jordan play, remembers the best moments of Jordan's career, knows Michael Jordan is the best NBA player ever, and that he is now staying at the hotel. All these mental states are factive, and involve Michael Jordan.

\footnotetext{
${ }^{6}$ It is unlikely that Segal wants to hold that, in general, a demonstrative that $F$, as uttered by $S$, demonstrates the $F$ which $S$ thinks is demonstratively present.
} 
Segal says that what explains object-oriented action is that one has a given singular belief that $P$, which is object-independent. Let it be Orville's belief that Michael Jordan is staying in the hotel. We must assume that this belief is available even on Twin-Earth where Orville's twin fails to refer to anyone. Now, if by chance someone is referred on Earth, Orville's belief is about what 'happens to be given by the context'. But he is in the same mental state as his twin, whether the context provides a referent for the name or not. So, Orville's twin should also stay up all night outside the hotel.

But let us turn the tables. What is available when Orville, like us, succeeds in talking about Michael Jordan? Orville is in several mental states, many of them factive. The states of knowing things about Michael Jordan are not equivalent to simply having beliefs about some unique individual called 'Michael Jordan' (which is the best basketball player ever, etc.) even if these beliefs 'happen to be true'. True belief is not sufficient for knowledge, as Gettier cases have taught us. We should not expect that adding truth, or justification, or other factors, to belief states will eventually yield knowledge states.

Knowledge arguably has a stronger explanatory power than belief, even belief that turns out to be true. The individualist's explanation of Orville's behaviour in staying up all night outside Michael Jordan's hotel combines the belief that Michael Jordan is staying in the hotel (and is the best player ever, etc.) with the fact that there happens to be someone supplied by the context (who actually is referred to with the name, is the best player ever, is staying in the hotel, etc.) But, if we take the lead from Williamson here (cf. Williamson 2000: $61 \mathrm{ff}$ ), it is more probable that Orville stays up all night outside Michael Jordan's hotel because he knows that Michael Jordan is staying there (and remembers all sort of facts involving Jordan), than it would be if he only believed that Michael Jordan was staying in the hotel, even if it happens to be true that Jordan is staying there.

Let us turn then to the individualistic explanation of behaviour. Object-independent singular beliefs, together with the fact that, in certain circumstances, they might happen to be true, cannot have the same explanatory and causal efficacy of genuinely broad mental states, such as knowledge. Since knowledge is factive, knowledge of facts involving individuals requires successful reference. Hence, the assumption that two subjects who are functionally and physiologically 
identical behave in the same way and are in the same mental states is problematic to defend. Object-independent mental states cannot perform as well as object-dependent mental states do in successful cases of reference. That being so, Segal's argument still does not establish that object-dependent thoughts are explanatorily redundant.

It is curious that Segal should insist on the meaningfulness of vacuous proper names, given that he accepts the view of the singularity and object-dependency of the truth-conditions of sentences with proper names (and other singular terms). In his work with Larson (Larson and Segal 1995), he endorses the Davidsonian thesis that the significance or meaning of a sentence can be accounted for by stating the necessary and sufficient conditions for its truth. Larson and Segal propose a cognitivized version of truth-conditional semantics, meant to account for speakers' knowledge. Thus, in putting forward the derivation of the truth-conditions for sentences, the theory is also putting forward what speakers understand by the uttered sentences.

The semantic values of sentences, truth-values, are assignable based on the values of constituent expressions and the rules for their composition into sentences. Predicates will be assigned semantic values by being associated to conditions of application that are general — indifferent to how many individuals meet the condition, and objectindependent - indifferent to which individuals meet the condition. The application conditions for definite descriptions are singular exactly one individual is described, but object-independent - indifferent to which individual is described. In contrast, proper names will be assigned semantic values by being associated with conditions of application that are singular - exactly one individual meets the condition, and object-dependent — the named individual is 'crucially involved'. ${ }^{7}$ This view is partly motivated by Kripkean anti-descriptivist arguments.

It is worth mentioning that Larson and Segal 1995 do consider a plausible alternative to McDowell's (that clauses stating the reference of names 'display their senses') to handle differences in cognitive value between co-referring proper names. This is the idea of a dossier of information associated by speakers to the use of a name. Even if names are not abbreviated descriptions, it is reasonable to hold that understanding an utterance with a proper name requires having some

\footnotetext{
${ }^{7}$ See Larson and Segal $(1995,127)$.
} 
conception of whom or what the name refers. The information in the dossier will be typically derived from the individual the name stands for, but it may include misinformation. That information will not fix the reference of the proper name, nor will it enter in the specification of the truth-conditions of utterances of sentences with that name. ${ }^{8}$

Perhaps the intuition that something is nonetheless understood even in the event of a singular term failing to refer can be accounted for by appealing to this notion of a dossier of information. As far as utterances of sentences with vacuous proper names are concerned, admittedly speakers do associate descriptive information with uses of names, even if there is nothing which is the source or causal origin of the body of information that speakers associate with the name. But that descriptive information is not part of the truth-conditions of utterances of (most sentences) with singular terms. This means that whatever else is understood in association with proper names, vacuous or not, goes beyond the statement of the contribution made by names to truth-conditions, and it seems to indicate that truth-conditional semantics does not account for all aspects of speakers linguistic competence.

Segal intends proper names to have conditions of application that are singular and object-dependent. But it is incoherent to hold this thesis simultaneously with the claim that proper names can make a meaningful contribution to sentences in which they occur whether or not reference is successful, and with the assumption that truthconditional semantics can adequately account for all aspects of speaker's linguistic competence.

Segal provides an alternative explanation to defend the individualistic assumption of the argument against SOT, supplementing it with a further explanation of how and why reference to existing external objects is relevant for the attribution of mental states. But it is doubt-

${ }^{8}$ Grice 1969 originally developed the notion of a dossier. Evans 1973, $1982 \mathrm{ch}$. 9, and Recanati 1993 explore the notion of a dossier of information associated with a proper name as a condition of the correct understanding of uses of the name. Thus, Evans says: We must allow then that the denotation of a name in the community will depend in a complicated way upon what those who use the term intend to refer to, but we will so understand 'intended referent' that typically a necessary (but not sufficient) condition for $x$ 's being the intended referent of S's use of a name is that $\mathrm{x}$ should be the source or causal origin of the body of information that S has associated with the name. (Evans 1973, 13) 
ful whether his solution for what does the further explanatory work is sufficient. Moreover, Segal's solution is at odds with his views on the semantics of proper names. So, Segal has not established that truthconditional object-dependent content is explanatorily redundant, or can be eliminated in favour of object-independent content. ${ }^{9}$

Teresa Marques Centro de Filosofia da Universidade de Lisboa Faculdade de Letras de Lisboa Alameda da Universidade, 1600-214 Lisboa teresamarques@fl.ul.pt

\section{References}

Blackburn, Simon. 1984. Spreading the Word. Oxford: Clarendon Press.

Burge, Tyler. 1986. Individualism and Psychology, The Philosophical Review 95: 3-45.

— 1977. Belief De Re. Journal of Philosophy 74: 339-62.

Carruthers, Peter. 1987. Russellian Thoughts. Mind 96: 18-35.

Evans, Gareth. 1973. The Causal Theory of Names. Aristotelian Society Suppl. Vol. 47: 187-208. Reprinted in Collected Papers. Oxford: Clarendon Press, 1-24.

- 1982. The Varieties of Reference. J. McDowell (ed.), Oxford: Clarendon Press.

Frege, Gottlob. 1892. On Sense and Meaning. In P. Geach and M. Black (eds.) Translations from the Philosophical Writings of Gottlob Frege. 1980 (3 ${ }^{\text {rd }}$ Edition), Oxford UK and Cambridge USA: Basil Blackwell, 56-78.

Grice, Paul. 1969. Vacuous Names. In D. Davidson and J. Hintikka (eds), Words and Objections. Dordrecht: Reidel, 118-45.

Kripke, Saul. 1980. Naming and Necessity. Oxford UK and Cambridge USA: Basil Blackwell.

Larson, Richard and Gabriel Segal. 1995. Knowledge and Meaning, an Introduction to Semantic Theory. Cambridge Mass.: MIT Press.

McDowell, John. 1977. On the Sense and Reference of a Proper Name. Mind 86: 159-85.

9 This paper was presented at ENFA3, Lisbon, June 2006, and at SIFA7, Cesano Maderno/Milan, in September 2006. I thank the audience at those occasions for questions and comments. I am particularly grateful to João Branquinho, Manuel GarciaCarpintero, Peter Sullivan and Célia Teixeira for discussion of the material in this paper. 
— 1982. Truth-Value Gaps. In L. J. Cohen, J. Łoś, H. Pfeiffer, I. P. Podewski (eds.) Logic, Methodology and Philosophy of Science VI. Amsterdam, New York and Oxford: North-Holland Publishing Company, 299313.

- 1984. De Re Senses. in C. Wright (ed.), Frege: Tradition and Influence. Oxford: Basil Blackwell, 98-109.

— 1986. Singular Thought and the Extent of Inner Space. In P. Pettit and J. McDowell (eds), Subject, Thought and Context. Oxford: Clarendon Press, 136-68.

Neale, Stephen. 1990. Descriptions. Cambridge Mass.: MIT Press.

Peacocke, Christopher. 1975. Proper Names, Reference and Rigid Designation. In S. Blackburn (ed), Meaning, Reference and Necessity. Cambridge: Cambridge University Press, 109-32.

Pettit, Philip. 1986. 'Broad-minded Explanation and Psychology', in Subject, Thought and Context, P. Pettit and J. McDowell (eds), Oxford: Clarendon Press, 17-58.

Recanati, François. 1993. Direct Reference. Oxford: Basil Blackwell.

Sainsbury, Mark. 2005. Reference Without Referents, Oxford: Clarendon Press.

Segal, Gabriel. 1989. The Return of the Individual. Mind 98: 39-57.

Williamson, Timothy. 2000. Knowledge and its Limits, Oxford: OUP. 